\title{
Dementia paralytica: deterioration from communicating hydrocephalus
}

\author{
SA N T I G O G I M É N EZ-R OLDÁN,CARLOS BENITO, \\ A N D MER CEDES MARTIN \\ From the Departments of Neurology and Neuroradiology, Ciudad Sanitaria Provincial, Madrid, Spain
}

SUMMARY Five patients suffering from dementia paralytica who failed to improve or deteriorated after one or several high dosage courses of penicillin, had pneumoencephalographic patterns suggesting communicating hydrocephalus. Measurements of the ventricular index, ratio of cella media to width of the temporal horn, and the callosal angle differed from that in seven cases of dementia paralytica with associated cerebral atrophy. An isotope cisternogram in three cases with communicating hydrocephalus further confirmed a blockage of the cerebrospinal fluid (CSF) at the parasagittal subarachnoid space. Three patients exhibited the full syndrome of gait apraxia, incontinence, and pyramidal tract signs associated with a severe degree of dementia. Shunting of the CSF in three cases was followed by immediate improvement in two, one in a longlasting way. No active parenchymal inflammation was observed in any of three brain biopsy samples taken during surgery, except for leptomeningeal fibrosis in one. Chronic leptomeningitis in dementia paralytica may impair subarachnoid CSF absorption with subsequent communicating hydrocephalus. Progression or inadequate responses after therapeutic doses of penicillin in dementia paralytica should prompt investigation for this complication as an alternative, effective treatment could be offered.

Treatment failures were recognised shortly after penicillin was introduced as the therapy of choice for neurosyphilis, the most dramatic being those cases in which the condition continued to progress despite seemingly adequate doses. There was usually no evidence of persistent changes in the cerebrospinal fluid (CSF), and subsequent courses of penicillin proved ineffective in arresting the condition. Progressive deterioration was observed in some $20 \%$ of cases of dementia paralytica after therapy (Dewhurst, 1969a) while 39\% had developed new neurological signs at long-term follow-up (Wilner and Brody, 1968). Furthermore, in a large series of patients with neurosyphilis progression occurred only in dementia paralytica but not in the other forms (Hooshmand et al., 1972). Accordingly, in $1953 \mathrm{Kral}$ and Dörken postulated that two different pathogenetic factors might be functioning in dementia paralytica. One factor, probably inflammatory in nature, would

\footnotetext{
Address for reprint requests: Dr S. Giménez-Roldán, Department of Neurology, Ciudad Sanitaria Provincial, Doctor Esquerdo 46, Madrid 30, Spain.

Accepted 20 November 1978
}

explain the acute clinical picture and CSF changes, being relatively responsive to therapy. A "longterm factor," unresponsive to therapy and unrelated to any appreciable inflammation, would account for cases with progressive deterioration. Even though residual vascular changes have been suggested (Merritt et al., 1937), the exact nature of such a long-term factor has not yet been defined.

In this paper we present five patients with dementia paralytica with no improvement or progressive deterioration after adequate penicillin therapy, in whom a syndrome of communicating hydrocephalus was found. Subsequently, a CSF shunting procedure provided some benefit in two of them.

\section{Patients and methods}

During the period 1969-1977, five patients with the diagnosis of dementia paralytica had a pneumoencephalogram suggesting communicating hydrocephalus. In two cases this diagnosis was made on a retrospective basis on reviewing their 
pneumoencephalograms. The clinical and radiological findings in seven other cases diagnosed as dementia paralytica and treated in the same period were used for comparison (dementia paralytica control subjects). The vast majority were neurological referrals from the Provincial Psychiatric Hospital, the largest mental hospital covering the Madrid area, because of gross organic central nervous system disease or unusual complications. This explains the great incidence of severe neurological abnormalities in our series.

The diagnosis of dementia paralytica in all 12 cases was based on neurological and laboratory findings, including various CSF abnormalities such as pleocytosis (five cases), increased protein content (nine cases), a paretic type of colloidal gold curve (seven cases), and increased $\gamma$-globulin levels (five cases). All 12 cases had positive immunoflourescent treponemal absorption test (FTA-ABS) in the CSF and serum, and usually also other positive serological tests for syphilis.

The pneumoencephalographic examinations were performed on a Mimer III DS-705 craneograph (Elema-Schönander, Siemens) with a targetfilm distance of $900 \mathrm{~mm}$. In agreement with Greitz and Grepe (1971) the pneumoencephalographic criteria for convexity block hydrocephalus were dilated lateral ventricles and absence of air filling over the convexities. Persistent efforts were made in every case to induce air filling of the cortical subarachnoid space. In this context the presence of cortical atrophy excluded the diagnosis of communicating hydrocephalus in this study. Both in the communicating hydrocephalus group and dementia paralytica control subjects the following measures were undertaken: frontal horn height, as seen in the lateral projection (Wood et al., 1974); the ventricular index, or the ratio of maximum skull width to the ventricular span, calculated by the method of Burhenne and Davies (1963); the callosal angle (LeMay and New, 1970); and the temporal horn-cella media ratio (Sjaastad et al., 1969). Results from both groups were compared using Student's $t$ test (significance at the $\mathrm{P}<0.05$ level).

Three communicating hydrocephalus patients and two dementia paralytica control subjects underwent a 169-Ytterbium (169 Yb-DTPA) cisternography with a linear scanner, measurements being taken serially at $6,12,24$, and 48 hours.

All dementia paralytica cases in this series were given large doses of penicillin (as detailed in Results), the magnitude depending on the individual response. Four patients with communicating hydrocephalus and two of the control subjects received aqueous crystalline penicillin-G intravenously in one or more courses, according to the programme proposed by Boudin (1966). In this, 30 megaunits of soluble penicillin are given intravenously in a $250 \mathrm{ml}$ isotonic glucose solution during a 30 day course. Doses of $1,3,5,10$, and 20 megaunits respectively, were given during the first five days. During the initial two weeks hydrocortisone hemisuccinate $(100 \mathrm{mg})$ was added to the perfusion fluid.

In three cases of communicating hydrocephalus a low pressure Holter ventricular valve was inserted and the CSF drained either to the left atrium (two cases) or the peritoneum (one case). A left frontal lobe biopsy sample was taken at the time of surgery from each case, and histologically processed.

\section{Results}

\section{CLINICAL FINDINGS}

The clinical and CSF findings in all five dementia paralytica cases having a pneumoencephalographic pattern of communicating hydrocephalus are given in Table 1. Pressure of CSF was recorded routinely in every case and none showed evidences of raised intracranial pressure. Patients with dementia paralytica and communicating hydro-g cephalus had a greater mean age at onset (a nine $\bar{\varnothing}$ year difference), and a shorter mean duration of the disease (19.6 and 29.6 months, respectively) $\overrightarrow{0}$ with respect to the control group, although there were wide variations (Table 2). Signs and symptoms which could be attributed to CNS syphilitic infection, such as the Argyll-Robertson pupil or dysarthic speech, were unevenly distributed in both dementia paralytica groups. On the other hand, signs frequently encountered in low pressure hydrocephalus of different aetiology such as gait apraxia, incontinence, pyramidal tract signs, and akinetic mutism (Hakim and Adams, 1965), were more commonly found in the patients with communicating hydrocephalus.

\section{PNEUMOENCEPHALOGRAMS}

None of the 12 dementia paralytica cases had a normal pneumoencephalogram. Convexity block, absence of demonstrable cortical atrophy, and gross ventricular dilatation defined the communicating hydrocephalic group, as exemplified in Fig. 1. All other seven dementia paralytica control subjects had cerebral atrophy of varying degree. In addition to diffuse widening of cortical sulci, five patients (cases 6 to 10) had enlarged ventricles (Fig. 2) or a hydrocephalus "ex-vacuo" pattern, while in two patients (cases 11 and 12) there was 
Table 1 Clinical and CSF findings in five dementia paralytica patients complicated by low pressure hydrocephalus

\begin{tabular}{|c|c|c|c|c|c|c|c|}
\hline \multirow[t]{2}{*}{ Case } & \multirow[t]{2}{*}{$\operatorname{Sex}$} & \multirow{2}{*}{$\begin{array}{l}\text { Duration of } \\
\text { illness }(\mathrm{mo})\end{array}$} & \multirow[t]{2}{*}{ Main clinical features } & \multicolumn{4}{|c|}{ Pretreatment CSF findings } \\
\hline & & & & $\begin{array}{l}\text { Cells } \\
\left(\mathrm{mm}^{3}\right)\end{array}$ & $\begin{array}{l}\text { Protein } \\
\text { content }(g / l)\end{array}$ & $\begin{array}{l}\text { Colloidal gold } \\
\text { curve }\end{array}$ & $F T A-A B S$ \\
\hline 1 & $\mathbf{M}$ & 65 & $\begin{array}{l}\text { Severe dementia. Dysarthria. Incontinence. Gait } \\
\text { instability. Argyll-Robertson pupil. Bilateral } \\
\text { Babinski sign. }\end{array}$ & 16 & 1.40 & Strongly paretic & $c+t$ \\
\hline 2 & $\mathbf{M}$ & 66 & $\begin{array}{l}\text { Severe dementia. Nocturnal incontinence. Argyll- } \\
\text { Robertson pupil. }\end{array}$ & 4 & 0.25 & Flat & ++ \\
\hline 3 & $\mathbf{M}$ & 34 & Moderate dementia. Chronic delirium. & 8 & 0.30 & Strongly paretic & +++ \\
\hline 4 & $\mathbf{F}$ & 64 & $\begin{array}{l}\text { Severe dementia. Dysarthria. Incontinence. } \\
\text { Generalized seizures. Bilateral pyramidal tract signs. }\end{array}$ & 2 & 0.30 & Mildly paretic & +++ \\
\hline 5 & $\mathbf{M}$ & 36 & $\begin{array}{l}\text { Severe dementia. Infrequent generalised seizures. } \\
\text { Dysarthria. Argyll-Robertson pupil. Right side } \\
\text { pyramidal tract signs. }\end{array}$ & 8 & 0.83 & Strongly paretic & $+t+$ \\
\hline
\end{tabular}

Table 2 Clinical data of dementia paralytica complicated by low pressure hydrocephalus and uncomplicated dementia paralytica

\begin{tabular}{|c|c|c|}
\hline Data & $\begin{array}{l}\text { Dementia paralytica } \\
\text { complicated by low } \\
\text { pressure hydrocephalus }\end{array}$ & $\begin{array}{l}\text { Uncomplicated } \\
\text { dementia paralytica }\end{array}$ \\
\hline Sex & $(n=5)$ & $(n=7)$ \\
\hline (male/female) & $4 / 1$ & $7 / 0$ \\
\hline \multicolumn{3}{|l|}{$\begin{array}{l}\text { Age at onset } \\
(\mathrm{yr})\end{array}$} \\
\hline Mean & 53 & 44 \\
\hline Range & $34-66$ & $31-56$ \\
\hline \multicolumn{3}{|l|}{$\begin{array}{l}\text { Duration of illness } \\
(\mathrm{mo})\end{array}$} \\
\hline $\begin{array}{l}\text { Mean } \\
\text { Range }\end{array}$ & $\begin{array}{l}19.6 \\
4-36\end{array}$ & $\begin{array}{r}29.6^{*} \\
2-72\end{array}$ \\
\hline Some neurological & Number observed/ & Number observed/ \\
\hline $\begin{array}{l}\text { abnormalities } \\
\text { Dementia }\end{array}$ & $\begin{array}{l}\text { number of patients } \\
5 / 5\end{array}$ & number of patients \\
\hline Gait instability & $2 / 5$ & $0 / 7$ \\
\hline Pyramidal tract & $3 / 5$ & $2 / 7$ \\
\hline Incontinence & $3 / 5$ & $1 / 7$ \\
\hline Dysarthria & $2 / 5$ & $4 / 7$ \\
\hline Seizures & $2 / 5$ & $0 / 7$ \\
\hline $\begin{array}{l}\text { Argyll-Robertson } \\
\text { pupil }\end{array}$ & $3 / 5$ & $4 / 7$ \\
\hline Tremor & $0 / 5$ & $2 / 7$ \\
\hline
\end{tabular}

*Unknown in one case.

only a pure cortical atrophy (Fig. 3).

Results of the different measurements are given in Table 3. Mean values for ventricular index and frontal horn height were abnormal, both for the communicating hydrocephalus group and control subjects, indicating that both groups had ventricular enlargement, but only the mean ventricular index values reached a statistically significant difference $(P<0.05)$. Three cases had anterior frontal horn values of $32 \mathrm{~mm}$ or greater, a feature suggested by Wood et al. (1974) for low pressure hydrocephalus. Normally, the callosal angle ranges between $130-140^{\circ}$, values under $120^{\circ}$ being sug-

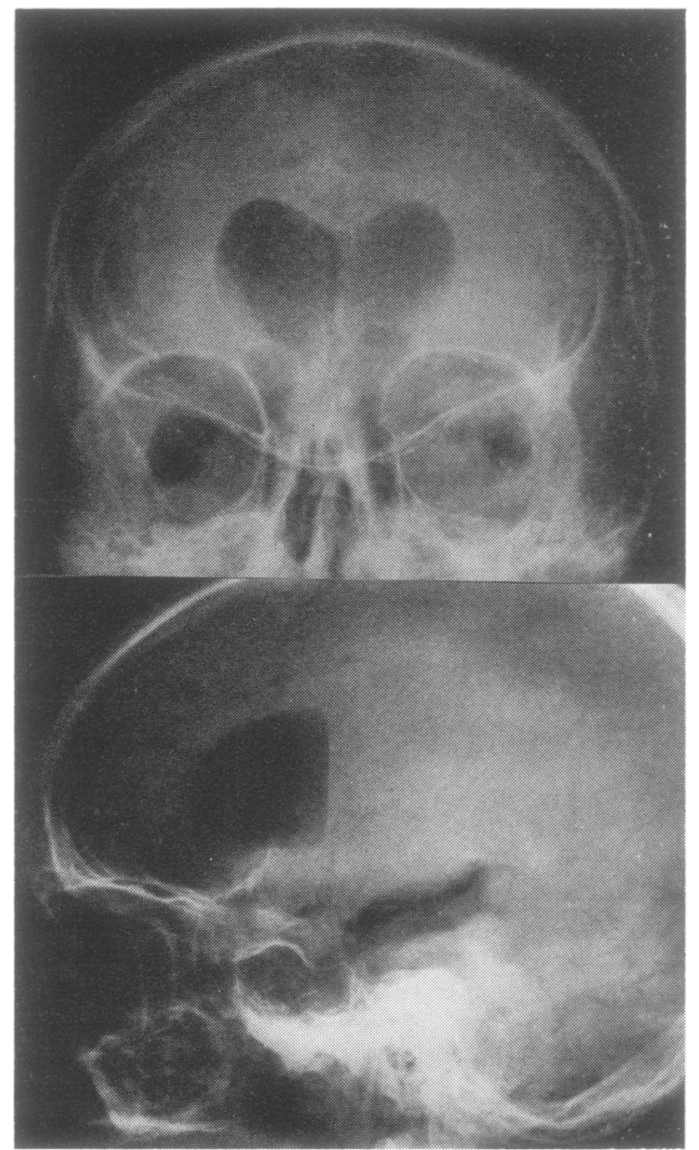

Fig. 1 Pneumoencephalogram (case 4) showing a low pressure hydrocephalus pattern. 


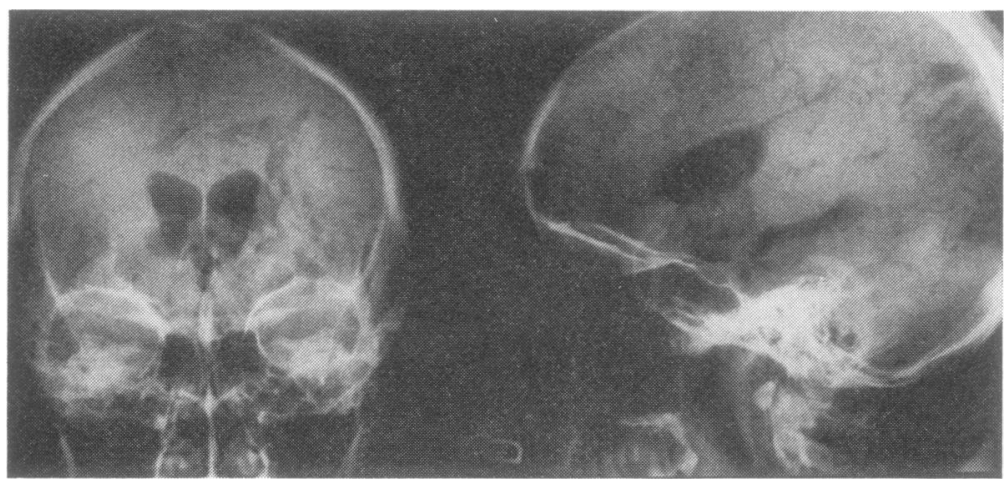

Fig. 2 Hydrocephalus "ex-vacuo" pattern (case 7) with diffuse widening of the cortical sulci.

Fig. 3 A cortical atrophy pattern (case 12) without appreciable ventricular enlargement.

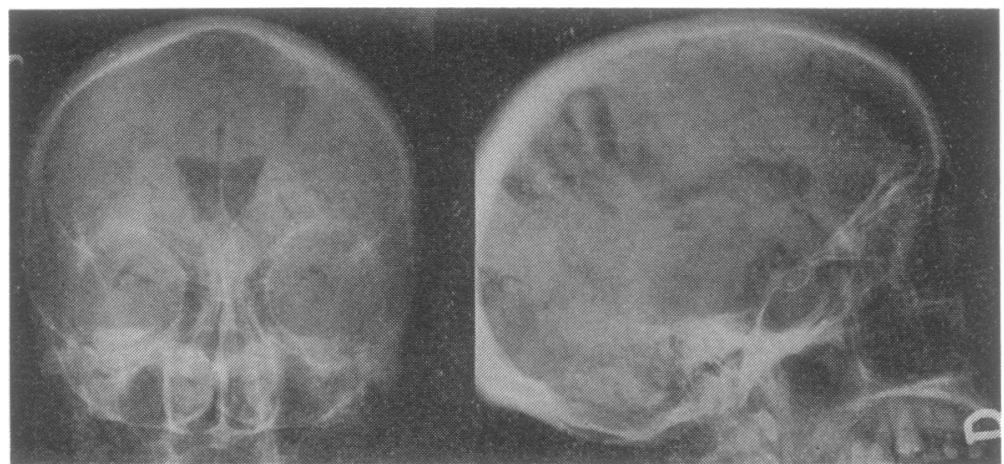

Table 3 Pneumoencephalographic indexes in dementia paralytica with associated low pressure hydrocephalus and cerebral atrophy

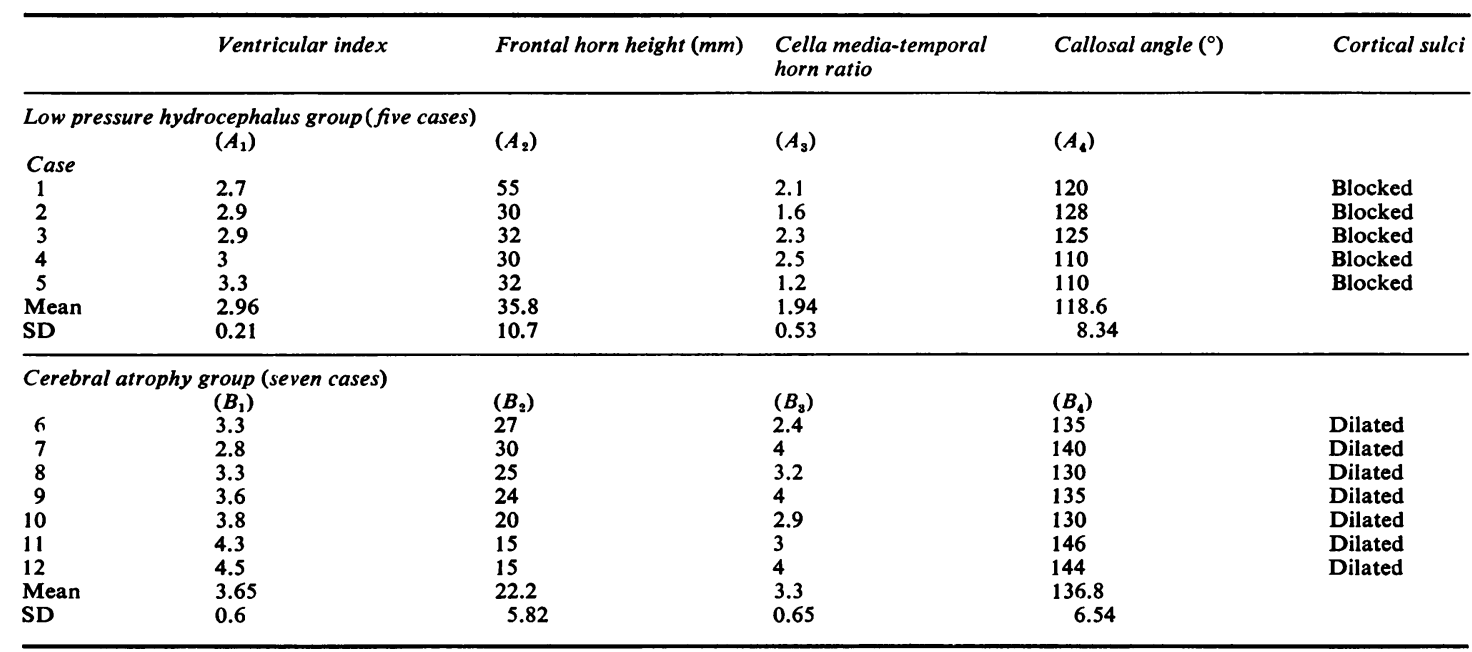

$P$ value $\quad A_{1}-B_{1}=P<0.05 \quad A_{2}-B_{2}=P<0.02 \quad A_{3}-B_{3}=P<0.02 \quad A_{1}-B_{4}=P<0.01$. 
gestive of low pressure hydrocephalus (LeMay and New, 1970). The mean value for our communicating hydrocephalus group of 118.6 falls well below the abnormal limit, and differs significantly $(P<0.01)$ from that in the dementia paralytica control subjects (136.8). The ratio of the width of the temporal horn to that of the cella media was found useful for the differential diagnosis of low pressure hydrocephalus from central cerebral ventricular enlargement (Sjaastad et al., 1969). In our series, mean values for communicating hydrocephalus $(1.94 \pm 0.53)$ also differed at the $\mathrm{P}<0.02$ level from that in the atrophic group (3.3 \pm 0.65$)$.

\section{ISOTOPE CISTERNOGRAPHY}

All three cases of communicating hydrocephalus in which isotope cisternography was done showed absence of parasagittal radioactivity as well as early ventricular entry of the radiopharmaceutical, with subsequent persistence for $\mathbf{2 4}$ hours or longer (Fig. 4). The isotope cisternogram was normal in one dementia paralytica control patient with no ventricular enlargement, and showed mild ventricular contamination at 24 hours in one other with hydrocephalus "ex-vacuo."

\section{MEDICAL AND SURGICAL TREATMENT}

The overall results in the present series of dementia paralytica with severe neurological involvement were generally poor, though both groups differed (Table 4). No case with communicating hydrocephalus improved as a result of penicillin therapy, and indeed two patients continued to deteriorate. The two instances in which a retrospective diagnosis of communicating hydrocephalus was made, had died within two years of their discharge to a chronic care centre. As a result of their lack of therapeutic responsiveness, communicating hydrocephalus patients received larger mean total dosage (668.7 megaunits) than the controls (120 megaunits), and all but one received one or more intravenous courses. In con-
Table 4 Results of therapy in dementia paralytica

\begin{tabular}{|c|c|c|}
\hline Treatment & $\begin{array}{l}\text { Low pressure } \\
\text { hydrocephalus } \\
(n=5)\end{array}$ & $\begin{array}{l}\text { Cerebral } \\
\text { atrophy } \\
(n=7)\end{array}$ \\
\hline \multicolumn{3}{|l|}{ Penicillin $G$} \\
\hline Mean dosage (MU) & 668.7 & 120 \\
\hline Range & 42.9-1.612 & $36-248.4$ \\
\hline \multicolumn{3}{|l|}{ Route } \\
\hline $\mathrm{i} / \mathrm{m}$ & 1 (case 3 ) & 5 \\
\hline $\mathrm{i} / \mathbf{v}$ & 4 & $\begin{array}{l}2 \text { (cases } 4 \\
\text { and 5) }\end{array}$ \\
\hline \multicolumn{3}{|l|}{ Results of medical therapy } \\
\hline Recovered & None & 2 \\
\hline Mild to moderate improvement & None & 2 \\
\hline Unchanged & 2 & $\overline{2}$ \\
\hline Progressed & 2 & 1 \\
\hline \multicolumn{3}{|l|}{$\begin{array}{l}\text { Results of ventricular shunt } \\
\quad(n=3)^{*}\end{array}$} \\
\hline Recovered & 1 & - \\
\hline Mild to moderate improvement & i & - \\
\hline Postoperative death & 1 & - \\
\hline
\end{tabular}

*Cases 1,4 , and 5 .

trast, two patients in the control group recovered to assume full employment, and two other patients obtained improvement in some degree. Progression of the disease, however, was observed in the follow-up of two other patients. With the exception of case 1 who continued to have high protein levels in the CSF, no other patient had persisting increased cell count or protein content after treatment, though paretic Lange curves remained in five cases and the FTA-ABS test persisted unmodified in all except two.

A dramatic recovery took place in case 1 after the CSF shunting procedure. $\mathrm{He}$ was in a state of akinetic mutism after a five month history of paranoid delusions followed by gait apraxia and incontinence. A subdural haematoma was drained successfully three months after the first operation, and he remains asymptomatic after a 30 month follow-up. Case 4 regained sphincter control and improved in her mental status, but after one week she developed a meningeal infection and the shunt was removed. Her family refused further opera-

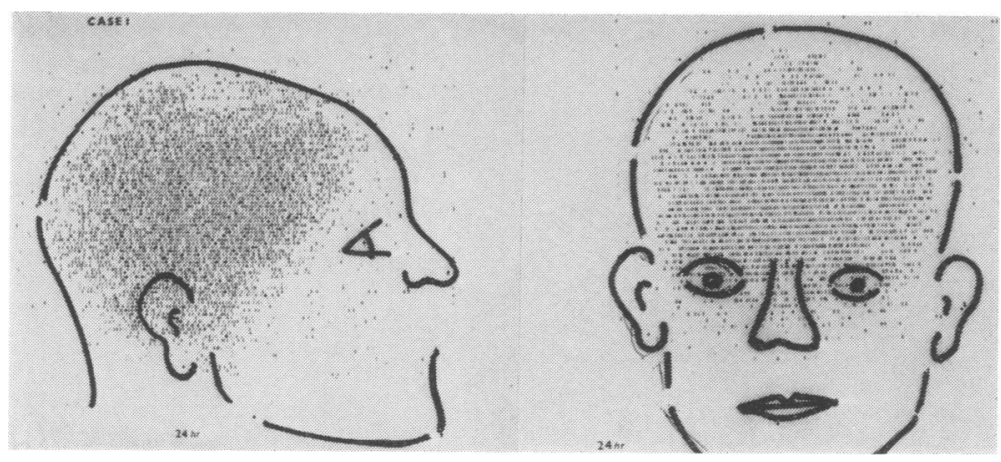

Fig. 4 169-Yb cisternogram in case 1 taken at 24 hours. Absence of isotopic activity over the parasagittal area as well as ventricular contamination can be seen. 
tions. Case 3 developed a large subdural haematoma after operation, became comatose, and died despite drainage.

\section{PATHOLOGICAL FINDINGS}

Biopsy specimens taken at the time of surgery from the three operated cases included grey and white matter and the overlaying leptomeninges. In two there was no evidence of persistent inflammatory parenchymal infiltration, but in the third (case 5) mild changes were found, consisting of diffuse astrocytic proliferation and a fibrous thickening of the leptomeninges (Fig. 5).

\section{Discussion}

All five patients with dementia paralytica reported here should be regarded as classic therapeutic failure, since large dosage intravenous (four cases) or intramuscular soluble penicillin given for one month or longer failed to achieve improvement in any case, and two of them continued to deteriorate. This occurred despite evolution of previous CSF inflammatory changes toward normality, though this appears to be no absolute guarantee as spirochetes have been isolated from patients with otherwise normal CSF (Tramont, 1976). Occasionally, progressive cases have been explained on the basis of insufficient dosage (Dewhurst, 1969b) or short duration of the course (Gager et al., 1968), but this was unlikely to explain the therapeutic failure in our cases, where one or more monthly courses and very large doses were given. A high dosage intravenous penicillin programme for 30 days, as advocated by Boudin (1966) was given in four cases. This avoids the low concentration of penicillin in the CSF when it is given intramuscularly, instead of intravenously (Mohr et al., 1976), and is currently recommended for therapeutically resistant cases of neurosyphilis (Center for Disease Control, 1976).

The diagnosis of dementia paralytica in our series was made on the basis of mental and neurological symptoms found in association with inflammatory changes in the CSF and a positive fluorescent treponemal antibody absorption test (FTA-ABS). This is currently the most reliable laboratory test for the diagnosis of neurosyphilis (Escobar et al., 1970), and appears more sensitive than the treponemal immobilisation (TPI) and other quantitative flocculation tests (VDRL) which occasionally have been negative in pathologically proven dementia paralytica (Ch'ien et al., 1970).

The pneumoencephalographic pattern of severe ventricular dilatation and subarachnoid blockage at the brain convexity was unlikely to be explained solely on the basis of uncomplicated dementia paralytica. Indeed, Taveras and Wood (1976) indicated that general paresis frequently produces disproportionate enlargement of the cerebralo os subarachnoid space as compared with ventricula융 size, through cortical atrophy, though widening? of cortical sulci and enlarged ventricles were occasionally found by others (Ch'ien et al., 1970 Venkoba Rao et al., 1972). Both these patterns were present in our control group. However, un like their series, our five cases with communicating $\overrightarrow{6}$ hydrocephalus conformed better to convexity blocke hydrocephalus. (Greitz and Grepe, 1971), and results of isotope cisternograms, when performed, were also in keeping with this diagnosis. When other features such as the ventricular index, ratio

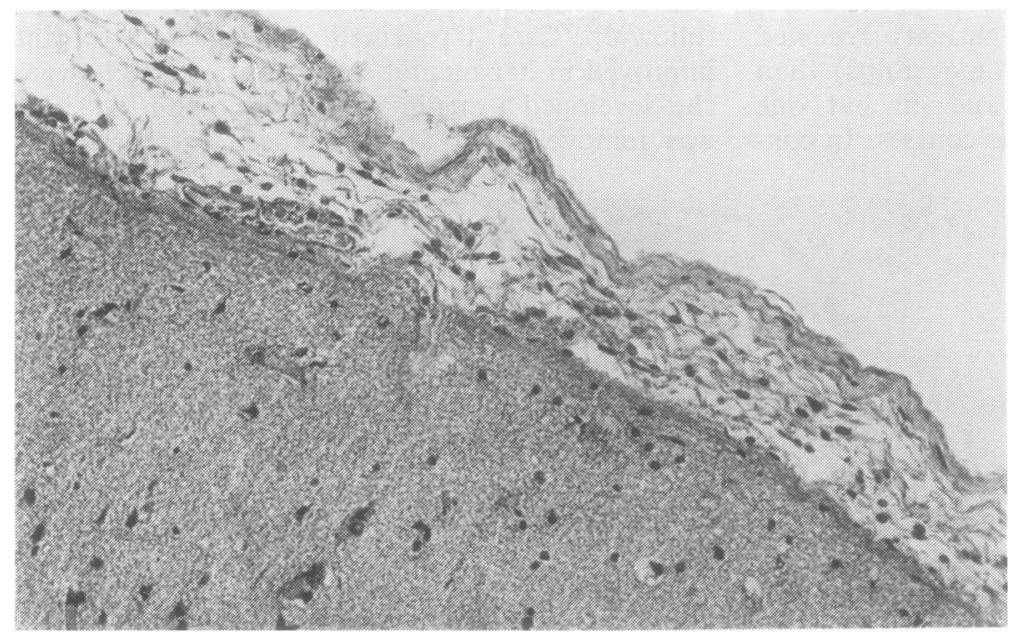

Fig. 5 Brain biopsy (case 4) showing absence of parenchymal inflammatory infiltration and thickening of the leptomeninges. $H$ and $E$, original magnification $\times 300$. 
of width of the temporal horn to cella media, and the callosal angle were compared with those from the dementia paralytica control subjects with cerebral atrophy, significant differences were also demonstrated.

Some clinical differences between both groups also became apparent. Cases with communicating hydrocephalus had a later onset and a more rapid progression, three cases becoming severely disabled after only 12 months of illness. Our case 1 with subacute progression resembled some of the six rapidly progressive cases of neurosyphilitic psychosis reported by Dewhurst (1968a), in which rapidly impending dementia appeared in combination with ataxia, increased deep reflexes, and bilateral Babinski responses. Boudin and Arfouilloux (1970) found rapidly expanding ventricles in a similar case as seen in subsequent pneumoencephalographic examinations. In adaddition to dementia, such symptoms as dysarthria, seizures, or Argyll-Robertson pupils were found in our patients regardless of their pneumoencephalographic and isotope cisternographic findings, as would be expected in central nervous system syphilis. On the other hand, the syndrome of gait apraxia, incontinence and pyramidal tract signs, as described in low pressure hydrocephalus (Hakim and Adams, 1965) was found in three out of five cases in our group.

In our cases, as well as in some other similar reports (Bruetsch, 1949; López Zanón et al., 1964; Dewhurst, 1969b), a syndrome of communicating hydrocephalus appears to develop on top of the otherwise well-known clinical and CSF features of chronic syphilitic meningoencephalitis. Lack of response or progression occurs after a correctly programmed penicillin course and, as a rule, these cases no longer had CSF abnormalities. There have been two post-mortem examinations from similar cases. They failed to disclose an active parenchymal inflammation, but only dilated cerebral ventricles and a diffuse, lattice-like thickening of the leptomeninges over the brain were found (Bruetsch, 1949; Dewhurst, 1968b). Examination of brain biopsy samples in three of our patients led to similar conclusions, as the only abnormality found consisted of leptomeningeal fibrosis and mild diffuse astrocytosis in one case.

Chronic leptomeningitis and subsequent fibrosis is a well-known pathological feature of general paresis (Harriman, 1976). This probably led in our cases to impairment of CSF absorption at the arachnoid villi with development of convexity block hydrocephalus and symptoms otherwise unresponsive to penicillin. A similar mechanism has been incriminated in hydrocephalus after meningoencephalitis from various causes (Hill et al., 1967; Lehrer et al., 1967), and more recently, in a large surgical series, a case secondary to dementia paralytica is included (Udvarhelyi et al., 1975). Accordingly, we suggest that patients with dementia paralytica showing insufficient response or progression after an adequately programmed course of penicillin, should be investigated for associated communicating hydrocephalus, as recognition of this complication could lead to a surgically effective therapeutic measure.

\section{References}

Boudin, G. (1966). Aspects actuels de la syphilis nerveuse et de son traitement. Revue de Practitien (Paris), 16, 3099-3106.

Boudin, G., and Arfouilloux, J. C. (1970). Neurologie. In Encyclopédie Médico-Chirurgicale: Paris.

Bruetsch, W. L. (1949). Penicillin or malaria therapy in the treatment of general paresis. A clinicoanatomic study. Diseases of the Nervous System, 10, 366-371.

Burhenne, J. A., and Davies, H. (1963). The ventricular span in cerebral pneumography. American Journal of Roentgenology, 9, 1176-1184.

Center for Disease Control (1976). Syphilis: recommended treatment schedules, 1976. Annals of Internal Medicine, 85, 94-96.

Ch'ien, L., Hathaway, B. M., and Israel, C. W. (1970). Seronegative dementia paralytica: report of a case Journal of Neurology, Neurosurgery, and Psychiatry, 33, 376-380.

Dewhurst, K. (1968a). Rapidly progressive cases of neurosyphilitic psychoses. Psychiatria Clinica, 1, 320-326.

Dewhurst, K. (1968b). Clinico-pathological aspects of neurosyphilitic psychoses. Postgraduate Medical Journal, 44, 898-902.

Dewhurst, K. (1969a). The neurosyphilitic psychoses today. A survey of 91 cases. British Journal of Psychiatry, 115, 31-38.

Dewhurst, K. (1969b). Treatment of the neurosyphilitic psychoses. Acta Psychiatrica Scandinavica, 45, 62-74.

Escobar, M. R., Dalton, H. P., and Allison, M. J. (1970). Fluorescent antibodies test for syphilis using cerebrospinal fluid. Correlation in 150 cases. American Journal of Clinical Pathology, 53, 886890.

Gager, W. E., Israel, C. W., and Lawton Smith, J. (1968). In Neuro-Ophthalmology. Symposium at the University of Miami and the Bascon Palmer Eye Institute, vol. 4. Edited by J. Lawton Smith, C. V. Mosby: St Louis.

Greitz, T., and Grepe, A. (1971). Encephalography in the diagnosis of convexity block hydrocephalus. Acta Radiologica (Diagnosis), 11, 232-242.

Hakim, S., and Adams, R. D. (1965). The special clinical problem of symptomatic hydrocephalus with normal cerebrospinal fluid pressure. Observa- 
tions on cerebrospinal fluid hydrodynamics. Journal of the Neurological Sciences, 2, 307-327.

Harriman, D. G. F. (1976). Bacterial infections of the central nervous system. In Greenfield's Neuropathology. Edited by W. Blackwood and J. A. N. Corsellis. Edward Arnold: London.

Hill, M. E., Lougheed, W. M., and Barnett, H. J. M. (1967). A treatable form of dementia due to normal pressure communicating hydrocephalus. Canadian Medical Association Journal, 97, 1309-1320.

Hooshmand, H., Escobar, M. R., and Kop, S. W. (1972). Neurosyphilis: a study of 241 patients. Journal of the American Medical Association, 219, 726-729.

Kral, V. A., and Dörken, H. (1953). Deterioration in dementia paralytica. American Journal of Psychiatry, 109, 684-692.

Lehrer, H., Larson, P. F., and McGarry, P. A. (1967). Cryptococcal meningoencephalitis. Two new radiological signs. Radiology, 88, 531-535.

LeMay, M., and New, P. F. (1970). Radiological diagnosis of occult normal-pressure hydrocephalus. Radiology, 96, 347-358.

López Zanón, A., Mantz, J. R., González Elipe, J., Cañada, L. A., and López Peñalver, J. J. (1964) Algunos aspectos actuales de la parálisis general progresiva. Hospital General (Madrid), 4, 610-626.

Merritt, H. H., Putman, T. J., and Campbell, A. C. P. (1937). Pathogenesis of the cortical atrophy observed in dementia paralytica. Archives of Neurology and Psychiatry (Chicago), 37, 75-90.
Mohr, J. A., Griffiths, W., Jackson, R., Saadah, H., Bird, P., and Riddle, J. (1976). Neurosyphilis and penicillin levels in cerebrospinal fluid. Journal of the American Medical Association, 236, 2208-2209.

Sjaastad, O., Skalp, I. O., and Engeset A. (1969). The width of the temporal horn in the differential diagnosis between pressure hydrocephalus and hydrocephalus "ex-vacuo". Neurology (Minneapolis), 19, 1087-1093.

Taveras, J. M., and Wood, E. H. (1976). Diagnostic Neuroradiology, vol. 1. Williams and Wilkins: Baltimore.

Tramont, E. C. (1976). Persistence of Treponema pallidum following penicillin-G therapy. Journal of the American Medical Association, 236, 2206-2207.

Udvarhelyi, G. B., Wood, J. H., James, A. E., and Bartlet, D. (1975). Results and complications in 55 shunted patients with normal pressure hydrocephalus. Surgical Neurology, 3, 271-275.

Venkoba Rao, A., Ranganathan, P. S., and Natarajan, M. (1972). General paresis in the psychiatric department of a general hospital. British Journal of Psychiatry, 121, 143-146.

Wilner, E., and Brody, J. A. (1968). Prognosis of general paresis after treatment. Lancet, 1, 1370 1371.

Wood, J. H., Bartlet, D., James, A. E., and Udvarhelyi, G. B. (1974). Normal-pressure hydrocephalus: diagnosis and patient selection for shunt surgery. Neurology (Minneapolis), 24, 517-526. 